\title{
Editorial
}

\section{Internacional A}

\begin{abstract}
A ciência, a ciência, a ciência... Ah, como tudo é nulo e vão! A pobreza da inteligência Ante a riqueza da emoção!

Aquela mulher que trabalha Como uma santa em sacrifício, Com tanto esforço dado a ralha! Contra o pensar, que é o meu vício!

A ciência! Como é pobre e nada! Rico é o que alma dá e tem.
\end{abstract}

Fernando Pessoa, A Ciência

Com enorme alegria recebemos o resultado da avaliação de nossa revista - classificada como Internacional A - pela comissão CAPES/ANPEPP. A notícia chega em esplêndido momento no qual vemos mais uma vez recompensados os grandes esforços empreendidos por mais de duas décadas em efetivas conquistas.

Lançada em 1985, a revista Psicologia: Teoria e Pesquisa vem, desde então, divulgando um número significativo de artigos inéditos (relatos de pesquisa e experiência profissional, estudos teóricos e revisões críticas da literatura) de pesquisadores brasileiros e estrangeiros, resenhas, notas técnicas e notícias em Psicologia e áreas afins. A expansão da revista Psicologia: Teoria e Pesquisa foi impulsionada pela versão eletrônica do periódico, disponibilizada desde a integração, em 2000, na coleção Scientific Electronic Library Online (projeto BIREME/FAPESP e CNPq) - SciELO - uma das mais geniais idéias de pesquisadores brasileiros que está prestes a cumprir 10 anos de existência e cuja missão, dentre outras, é publicar as coleções dos melhores periódicos on-line dos países iberoamericanos e, com isso, contribuir para o avanço científico, tecnológico e social de nações em desenvolvimento.

Por sua vez, a revista Psicologia: Teoria e Pesquisa garantiu sua visibilidade e divulgação no âmbito nacional e internacional, a partir de sua inclusão em indexadores nacionais e internacionais, tais como PsycINFO (American Psychological Association), Ulrich's International Periodicals Directory, Pascal e Francis - disponibilizados pelo Institut de l'Information Scientifique et Technique (INIST), organismo vinculado ao Centre National de Recherche Scientifique (CNRS) da França -, DARE (UNESCO), LILACS (BIREME), e-Psyc INFO e Index Psi (Conselho Federal de Psicologia/ USP).

Desde este ano, a revista passa a ter periodicidade trimestral e, aliada a todas as características que a fazem uma referência na área de Psicologia, espera adentrar, de forma definitiva, no mais alto patamar de excelência que um periódico científico poderia alcançar.

Neste segundo exemplar de 2007, o leitor poderá apreciar artigos de autores(as) nacionais e internacionais dos mais diversos saberes da Psicologia. Na área da Psicologia Jurídica, Clarissa De Antoni, Luciana Barone e Sílvia Koller analisam os indicadores de risco e de proteção identificados em famílias com denúncia de abuso físico parental. Leila de Brito, por usa vez, aborda o significado da medida socioeducativa de liberdade assistida no contexto da doutrina de proteção integral.

Na área da Psicologia da Saúde, Ana Paula de Matos e Ana Cláudia Machado apresentam um estudo sobre a relação das variáveis sócio-demográficas, clínicas e psicológicas com a qualidade de vida do doente asmático.

Lívia Gomes e Nelson Júnior discutem a possibilidade da amizade se configurar como espaço de experimentação política. Maria da Consolação André traz reflexões a partir da apresentação de acontecimentos sócio-históricos do sistema escravista percorrendo os ângulos sociológico e psicológico.

$\mathrm{Na}$ área clínica e psicanalítica, Jaqueline Rossi apresenta argumentos para afirmar que Freud, para fornecer uma explicação clinicamente eficaz para a histeria, progride da neurologia para a psicologia. João Neto, por seu turno, se propõe a desenvolver um estudo conceitual dos diversos enfoques presentes na obra de Foucault para o estudo das práticas clínicas. Mônica Macedo e Blanca Werlang abordam a tentativa de suicídio considerando-o um ato-dor decorrente da vivência de situações traumáticas.

No âmbito dos processos mentais e da análise experimental do comportamento, Gerson Janczura, Goiara de Castilho, Nelson Rocha, Terezinha van Erven e Tin Po Huang apresentam normas de concretude para 909 palavras coletadas utilizando-se uma escala de julgamento. Valdete Oliveira e Luiz Carlos Albuquerque investigam variáveis que podem interferir no seguir regras. Maria Regina Cavalcante e Mariana Carrara averiguam os efeitos da modelagem do comportamento verbal e das instruções sobre o comportamento verbal e o não-verbal de crianças de 8 e 9 anos.

$\mathrm{Na}$ área de medidas em Psicologia, Ronaldo Pilati e Jacob Laros apresentam e discutem as possibilidades de aplicação de modelos de equações estruturais na Psicologia e em ciências correlatas.

Por fim, Ana Raquel Torres faz uma resenha sobre a obra intitulada "Psicologia Social: Perspectivas Psicológicas e Sociológicas" de Luis Álvaro e a Alícia Garrido, na qual os autores se propõem a discutir criticamente o desenvolvimento histórico dessa disciplina relacionando os seus principais desdobramentos teóricos com as concepções epistemológicas e metodológicas vigentes em cada momento dessa história.

Desejo a todos uma ótima leitura!

$$
\begin{gathered}
\text { Maria Inês Gandolfo Conceição } \\
\text { Editora }
\end{gathered}
$$

\section{Referência}

Pessoa, F. (1981): Obra Poética. Rio de Janeiro: Ed. Aguilar. 